\title{
Family members' perspectives on potential discussions about life prolongation for their older relatives
}

\author{
Diane Garrnet, Tushna Vandrevala, Sarah E. Hampson, Tom Daly, \\ Sara Arber, University of Surrey
}

\begin{abstract}
Family members (or health-care confidants) of incapacitated patients are often consulted by doctors when making life-prolongation decisions. Little research has been conducted on confidants' views on life prolongation and advance care planning. This study investigated the health-care confidant's view on life prolongation and their involvement in being a potential decision-maker for their relatives in the event of incapacitation. Confidants ( $\mathrm{N}^{1 / 4}$ 12) were interviewed and interviews were analysed using Interpretative Phenomenological Analysis. The analysis revealed three themes relating to their perception of being a potential decision-maker for a relative's life prolonging measures: "good"' and "bad" death based on past experience and perceptions of quality of life, a sense that discussions were inappropriate at present, and strategies which might be used to encourage discussion. The implications of these findings for family involvement in life-prolongation decisions and how to encourage family discussions about life prolongation are discussed.
\end{abstract}

\section{Background}

Advances in medical technology have led to an increase in life expectancy in developed countries. However, life can be prolonged with little regard to quality or the patients' autonomy. Advance care planning (ACP) offers possible solutions to ensure that the dying process is according to patients' wishes. ACP provides opportunities to people to specify preferences about future care and treatment, especially towards the end of life. There is widespread recognition of the importance of ACP within current European (e.g., European Federation of Older Persons, 2004) and UK policy agendas (e.g., Department of Health, 2001, 2005; National Health Service, 2005, 2006). These policies and guidelines call for recognition of older people's rights to be informed about, and involved in, decision-making about their care in later life, and are concerned with the maintenance of dignity by ensuring choice and careful care planning. 
Fewer directives and legislations suggest that family members should be involved in decision-making in later life. When the patient is incapacitated, British Medical Association guidelines advise that family members (i.e., healthcare confidants) should be consulted prior to decisions about resuscitation being made (British Medical Association, 2007). Confidants are expected to communicate on behalf of the patient and to reflect what they know about the patients' previously expressed wishes, which suggests that discussions about life prolongation should have taken place prior to incapacitation. The guidelines on family involvement with respect to withholding other life-prolonging medical treatment such as artificial feeding and ventilation are less clear. These state that a well-documented advance refusal of treatment is valid if made by a mentally competent and informed adult (British Medical Association, 2007). These guidelines do not address the family or confidants' involvement with regard to other life-prolonging medical technologies. Additionally, the Mental Capacity Bill (House of Commons, 2004), fully implemented in October 2007, suggests that, besides financial matters, Lasting Power of Attorney extends to resuscitation measures and continuation of life-prolonging treatment, but only when the advance directive contains express provision to that effect. In practice, medical professionals tend to consult with family members before making decisions on life prolongation for their incapacitated relatives.

Advance directives or living wills can be made to ensure that patients' care at the end of life is in accordance with their wishes, assisting both medical staff and proxy decision makers. However, few people make or sign living wills (e.g., Luttrell \& Summerville, 1996; Palker \& Nettles-Carson, 1995) and most only discuss endof-life care if the issue is brought up by medical professionals (e.g., Volicer et al., 2002). Research has suggested that involving family members in discussions about life prolongation helps patients and healthcare professionals broach these sensitive issues without unnecessarily alarming or compromising the defence mechanisms of the patient (Kohn \& Menon, 1988). Therefore, family members tend to get involved in advance care planning only in the event of the patient being incapacitated. Proxy decision-making is legal in the USA and, in some US states, proxies have the authority to discontinue life-prolonging treatments (Curtis \& Burt, 2003). In contrast, the legal status of family members in life-prolonging decision-making is ambiguous in the UK.

Research in the USA suggests that older people are more likely to want their families to make decisions at the end of life for them than doctors (e.g., Cicirelli, 1997; Emanuel \& Emanuel, 1992; High, 1988; Puchalski et al., 2000). For example, Volicer et al. (2002) found that $90 \%$ of patients preferred family members to doctors as surrogates for decision-making in later life. In the UK, older people living in the community would rather discuss resuscitation issues with family members who can act on their behalf than their doctors (Seymour et al., 2004; Vandrevala et al., 2006). In addition, older patients receive advice on 
life prolongation from family members (Keith, 1983) and the family role in endof-life decision-making increases with dependency (Pratt et al., 1989) and incompetence (High, 1994). Seriously ill and older patients may not make advance care directives because they trust their families to make decisions for them (SUPPORT, 1995). In long-term care facilities, medical professionals routinely rely on family members to serve as proxy decision-makers for residents with dementia or other illness (Emanuel \& Emanuel, 1992).

The literature on confidant decision-making at the end of life suggests that many older people use a hierarchical order of preference when choosing confidants, preferring spouses, daughters over sons, sisters over brothers, and older children over younger (High, 1988; Roberto, 1999). Marital status and parenthood are important factors when choosing confidants to make decisions on their behalf (Wenger \& Jerrome, 1999). Having a confidant is associated with improved mental health (Carpiniello et al., 1989; Guarnaccia \& Zautra, 1989), combats depression and psychological dis- tress, and may provide social support to older people at the end of life (Allen \& Shuster, 2002; Wenger \& Jerrome, 1999). However, being a confidant may be less beneficial. Many confidants are also carers, ranging from occasional visitors to full time caregivers. Continuous care can place a burden of physical, emotional, and financial strain on the carer as individuals become more impaired and the burden on the carer increases (Edelmann, 2000). Difficulties are compounded if the carer also becomes the surrogate decision-maker facing the emotional strain of being part of a Do Not Attempt Resuscitation (DNAR) decision for the person for whom they are proxy. The stress of these situations can be mitigated when discussions have taken place in advance especially if these have been documented (Volicer et al., 2002).

Research has been directed at assessing confidants' ability to predict accurately their family members' choices about life prolongation (e.g., Ditto et al., 2001; Seckler et al., 1991; Uhlmann et al., 1988). These concordance studies consistently revealed low-to-moderate agreement between a patient's choice and the confidant's decision (e.g., Seckler et al., 1991; Uhlmann et al., 1988). Given the modest levels of agreement found in these studies, the potentially stressful role of being a confidant with regard to decisions about life prolongation, and the relative paucity of research related to healthcare confidants as proxy decision makers particularly in the UK, further investigation into the confidant experience is needed. This study was designed to begin to address this gap by using a qualitative approach to explore discussions on life prolongation from the confidant's perspective. The findings suggest insights into how it might be made easier for confidants and their relatives to discuss life prolongation prior to a crisis or severe ill health.

\section{Method}

Ethical approval was sought and granted by the South-West Surrey Research Ethics Committee. 


\section{Participants and recruitment}

This study was part of a series of studies addressing older people and their confidants' (family members) views on life prolongation and discussing these issues with each other. The participants for this study (confidants) were nominated by their older relative. The older relatives, aged 65 years old and over, were recruited from General Practices in South East England in a lower socio-economic area. They were invited by letter from their GP to return a postcard with their contact details if they were interested in participating in the study. Participants were asked to nominate a confidant (family member) whom they would like to be involved in decisions regarding life prolongation, and their confidants were then invited to participate. The eligibility criteria for the confidants were that they were generally in good health, able to read and comprehend English, lived in the community, did not suffer from dementia, any cognitive disability, or depression, and had not recently suffered bereavement. There was no age restriction on confidants. Confidants were interviewed separately to their older relatives. Only data from the confidants are presented in this report.

Twelve confidants were interviewed: three men (partners/spouses), and nine women, comprising four daughters, one sister-in-law, and four spouses. Their ages ranged from 45-78 years (mean age 65 years). All but one had completed secondary school but none had any college level education. Eight were retired, three worked part-time, and one full-time. Present or past occupations were manual or clerical. All described themselves as "white" and either Protestant or Catholic (Christian).

\section{Semi-structured interviews}

Confidants' views on life-prolonging measures for people in general were explored, and their attitudes towards the use of ventilator machines, artificial feeding, and cardiopulmonary resuscitation (with explanations provided if necessary) for their relatives. They were encouraged to discuss their potential involvement in decision- making for their relatives and whether they would discuss life prolongation with their relatives. Participants were encouraged to consider the factors they would take into account in decision-making about life prolongation. Confidants were also asked to imagine having a hypothetical discussion about lifeprolonging measures, and potential problems which might be encountered. The interview schedule was semi-structured and non-directive; probes were used by the interviewer to encourage participants to provide a fuller and richer account of their perceptions.

All interviews were audiotaped and transcribed verbatim. All interviews took place in the confidants' homes. They lasted 45-60 minutes depending upon how much rapport developed with the interviewer, which resulted in differing amounts of free-flowing conversation. At the end of the interview, confidants were given an information sheet on cardiopulmonary resuscitation and a list of organizations that 
could provide information. They were also given the researcher's contact information and the option of a follow-up phone call the next day.

\section{Analytic Strategy}

Interpretative Phenomenological Analysis (IPA) was used to analyse the data. IPA is phenomenological in that it is concerned with trying to understand an individual's perspective on an issue, as opposed to attempting to produce an objective record of the event or state itself, with a view to getting closer to the participant's world (Smith, 1996). The interpretative aspect acknowledges the researcher's interpretative engagement with the participants' text (Smith, 1996). It is typically conducted on a relatively small, homogenous sample of interviews in which the interviewer explores a topic in depth following a semi-structured interview guide.

Following IPA procedures, the 12 transcripts were analysed (Smith, 1996; Smith et al. 1999). The steps included reading the transcripts several times and the analysis of each transcript began with initial thoughts, highlighting themes that were particularly interesting. These emerging themes were coded with a key word or phrase that broadly captured the theme. As a validation exercise, the researcher DG consulted with another researcher (TV) at this stage, who had analysed the data in the same way. The emerging themes were compared and discussed and an agreement was reached regarding their significance. If these emergent themes were repeatedly found across and within the interviews, they were noted as recurrent themes, as they represented shared understanding. Each recurrent theme was then selected for further in-depth, intensive analysis by re-reviewing the transcripts. This was done primarily by the first researcher DG. Material that was not previously selected was included. At this stage, some of the themes were recoded. The researcher DG continued to examine the transcripts for connections among these recurrent themes, which were established by considering their context. Groups of related recurrent themes were organized under a master theme. Interpretation of themes was illustrated by extracts from the transcripts. In the extracts, [. . .] indicates that material has been omitted, material in brackets ( ) was added for clarification by the authors, and pseudonyms are used to protect the identity of the participants.

\section{Findings}

Interpretative analysis revealed three overarching and related master themes. These reflected the confidants' perspectives on their potential involvement in making life-prolongation decisions for their relatives in later life. The majority of confidants had not discussed life prolongation with their relatives at present, however most were articulate about views on their potential involvement in the future. Their perspective will be discussed under the following master themes: previous experience of death and dying and the issue of quality of life, perceptions that discussing life prolongation with the family was inappropriate at present, and 
strategies which may be used to encourage discussion with relatives. These themes and their subthemes are summarized in Table I.

\section{Previous experience of death and dying and quality of life}

Confidants drew on their past experiences of the suffering and/or death of family members and friends. These experiences influenced views on what constituted a "good" or "bad" death, and also whether confidants would encourage the use of life prolongation in the future and/or discuss these issues with their relatives. Past experience in some cases influenced confidants' views that "saving"' a younger person using life-prolonging measures was intrinsically more valuable than saving an older, terminally ill person whose quality of life was already poor. Confidants had strong views on what constituted an acceptable quality of life, warranting the use of life-prolonging measures. For example, most confidants felt that life-prolonging measures would be less desirable if the result for the relative was cognitive impairment. For other confidants, accepting an inferior quality of life for a relative was preferable to losing them.

Perception of "good" and "bad" death. Confidants used narrative to illustrate the conflict they felt about their potential involvement in decisions on life prolongation for a dying relative. Wanting relatives to be revived by resuscitation competed with their wish to avoid prolonged suffering. Trajectories of suffering, illness, and death were used to make sense of this, and a theme of "good" (quick, peaceful) and "bad" (lingering, lack of control) deaths emerged. Daphne, who was acting as confidant to her stepfather, had witnessed cardiopulmonary resuscitation and ventilation procedures during her mother's death. Her more positive experience

Table I. Master themes and recurrent themes.

\begin{tabular}{ll}
\hline Master themes & Recurrent themes \\
\hline $\begin{array}{l}\text { Previous experiences } \\
\text { of death and dying }\end{array}$ & $\begin{array}{l}\text { Perceptions of a "good" and "bad" death } \\
\text { Death of the old and ill versus death of the young } \\
\text { Quality of life (concern for mental impairment, } \\
\text { accepting an inferior quality of life for a relative } \\
\text { rather than lose them) }\end{array}$ \\
$\begin{array}{l}\text { Relatives in good health } \\
\text { Perceptions that discussion } \\
\text { of life prolongation } \\
\text { with family inappropriate }\end{array}$ & $\begin{array}{l}\text { Adult children's reluctance to discuss with older relatives } \\
\text { at present }\end{array}$ \\
$\begin{array}{l}\text { Confidants consider possible } \\
\text { strategies which could be } \\
\text { used to encourage }\end{array}$ & $\begin{array}{l}\text { Making it less personal } \\
\text { discussion with relatives }\end{array}$ \\
\hline
\end{tabular}


when her "natural" father died influenced her thoughts about prolonging life for an incapacitated person: a good death was "dying with dignity”.

\begin{abstract}
Daphne: I think it's having dignity too .... to be able to live how you want to live... Sometimes I think that (it) was just too long, because mum [...] had been absolutely sick, and was unconscious. After that we knew there was no hope, and there was brain damage but they kept on resuscitation for a little while so we just said "no, turn it off". . . My natural father-he died of a heart attack, but it was very quick and very sudden, in fact the ideal death (tearful laugh) because you've got no idea, it just happens. I think my mum's death was much harder (Daughter, 47).
\end{abstract}

Confidants' perceptions of illness and death experienced by those close to them influenced thinking about potential life-prolongation decision-making. Experience of a relative's suffering in the final stages of life left a lasting mark. Elizabeth too recalls her father's suffering when asked what factors would influence her decision on life prolongation in the future.

Elizabeth: I personally, [...] depending on the situation, umm, [...] It’s like my father, his cancers were in the lungs and he was gradually [...] asphyxiating in his own fluids [...] having been close to my father, I was thinking, if only it could have been done quicker [...] So, if somebody is so ill that there is nothing anybody can do, I would like to do things to ease their pain (Daughter, 48).

Death of the old and ill versus death of the young. When speaking of involvement in decisions regarding life prolongation and possible incapacitation of an ill person in the future, most confidants wished for a peaceful death for an older person whilst in direct contrast wanting to "fight for life" in the case of the young. The experience of a death in the family often led to strong views on what was an acceptable way to die and influenced how confidants felt decisions would be made on whether life was worth fighting for. Elizabeth described her feelings about the death of her baby son, for whom she would have used any life-prolonging measure available. Her experience of his death had also made her more aware of her mortality and more accepting of it.

Elizabeth: If a baby died like my little boy did, what have I got to be frightened of? It's when elderly relations that died, I used to think that it was something to be frightened of. It's a weird thought, but if babies can do it, why have I got to be afraid of it?... Now if I had known the night before that his (son's) lungs were going to pack up that night, I would have had all the emergency people stood by just to make him keep going (Daughter, 48).

Quality of life. The quality of life which might be expected for an older relative who had received life-prolonging measures was of great concern to most confidants, primarily the chance of cognitive impairment or pain and suffering. However, confidants who were long-term spouses or carers would, in some instances, accept a lower quality of life for their loved ones rather than lose them. 
A recurrent theme with regard to quality of life was concern about mental impairment, confidants suggesting that life-prolonging measures would be less desirable if, as a result, the relative became mentally impaired. Every confidant mentioned cognitive problems or coma as the "worst scenario" for their relatives, often comparing mental problems to "being a cabbage", a "vegetable", or being in "a vegetative state". In these cases, death might be seen as preferable. For example, Terence had worked in a nursing home where dementia was common:

Terence: If you got to that stage [...] then you're better off [...] dead, 'cos they're a burden to everyone (Spouse, 71).

If it was probable that relatives were to experience constant pain and suffering after receiving life-prolonging measures, confidants were less likely to want to commit them to this choice.

Another recurrent theme regarding quality of life was the acceptance of an inferior quality of life for a relative rather than lose them. For the spouseconfidants, there was a discrepancy between confidants' attitudes to life prolongation for themselves and for their spouse/partner. Jim was strongly against resuscitation for himself:

Jim: My wife knows my feelings. I'd listen to her views, I'm not saying I'm going to agree with them (laughs heartily) I tend to get on my "high horse" [...] it would be me being dogmatic I expect.

Resuscitation for his wife, however, was different:

Jim: If there was a chance at the end of the tunnel I might say "yes, do it all". But I don't think I'd want her left as a cabbage (Spouse, 73).

For Jim and many other long-married couples, the prospect of facing the death of a spouse was extremely difficult and painful, despite knowing that if they lived their spouse would endure a poor quality of life. Resuscitation or other lifeprolonging technologies may be chosen by confidants rather than facing the pain of losing a loved one. Agnes (sister-in-law, 76) described her brother-in-law's reaction when asked if his wife (her sister) should be resuscitated, and in contrast points out that she felt that her sister's suffering was needlessly prolonged.

Agnes: He got very angry and said “you saved the Queen mother, why can’t you save her" and they said "well, would Margaret [. . .] want to die?" and they did it and she was really poorly [. . .] He was doing it, not cruelly, but he didn't want to lose her [...]. If you knew there wasn't much hope, what's the point, you know, just prolonging the suffering, this is what we did for my sister I feel. Somebody dying that's really close to you, it brings it home doesn't it (Sister-inlaw, 76). 
Fred lost his wife to cancer quite suddenly. She remained at home and he nursed her to the end. He explained how desperately he wanted her to live.

Fred: It was never meant to happen. (His wife had months to live.) You see [...] my wife was my life and we did things together. When they told me I said “you're wrong”. I didn't know what to do, not for her, for ME (Spouse, 72).

Most confidants did not want the life of their relatives prolonged if that life had no quality or involved pain and suffering. However, some spouse-confidants recognized that they might prefer the life of their spouse to be prolonged even if their quality of life was poor, and perhaps not something the confidant would want for themselves, thus protecting themselves from loss of a loved one.

Similarly, confidants who cared for disabled or chronically ill children or parents were supportive of using life-prolonging technologies even at the expense of quality of life, and supported actively fighting for life as they had done over the years for their relative. When Rose was asked if she ever thought about death, she answered:

Rose: With a handicapped son I've thought about (death) all the time, I would have thought that it is important to prolong life.

Asked about quality of life, she said:

Rose: It's still life, if you're happy, that's fine (Spouse, 70).

Perceptions that discussing life prolongation with the family was inappropriate at present

Relatives in good health. One of the 12 confidants had discussed these issues with their relative. Most confidants stated that as their relatives were currently reasonably healthy, there was no urgent need for such discussions. Spouseconfidants ( $\left.n^{1 / 4} 7\right)$ seemed to indicate that their partner would not want to talk about such things and there was no reason to at the moment, with the implication that they would have such discussions when the right time came. When asked if he had discussed life-prolonging measures with his wife, Terence replied:

Terence: No. I've no reason to. Because neither of us have got to the stage where we are thinking of nursing homes or anything (Spouse, 71).

Protecting oneself from the reality of losing a loved one. It seems reasonable to expect that confidants may not wish to discuss life prolongation with their relatives in the case of good health and this perhaps suggests that in the event of ill health, discussion regarding life prolongation may occur. However, some confidants suggested that even though they were aware of their relative's precarious state of health a conversation regarding life prolongation had not taken place. Iris, confidant for her 
husband, accepts that her husband, who has a heart condition, may potentially die before she does. She feels comfortable discussing funeral arrangements with her spouse but discourages conversations regarding life prolongation.

Iris: (The topic has) never arisen, I don't know that we have chosen not to. My husband's always said he would die before me, because he has had a problem. We've been to funerals we've discussed what he'd like, and what I'd like. Ummm, but it's never been an issue.

DG: Does he have ideas about life prolongation?

Iris: No, not really. No real reason other than, I suppose, if Ben talks about death I just say well “don’t worry about it, it’s not going to happen yet”' (Spouse, 60).

Adult children's reluctance to discuss with older relatives. Adult children confidants ( $n 1 / 44$ ) suggested that they were reluctant to discuss life prolongation with their parents. They perceived that their parents themselves would not want to talk about end-of-life issues, and they did not want to upset their parents. Myrtle speaks of avoiding the topic as her mother would find it unpleasant, although it would be helpful for Myrtle.

Myrtle: Mother's of the old school where you don't talk a lot about these things, whereas I am a different generation, it doesn't bother me so much, but I probably tend to keep away from it when I am talking to her, 'cos I don't want to upset her, you know (laughs) being of the older generation (Daughter, 65).

In these parent - child relationships, the adult child often did not want to initiate discussion on life prolongation, leaving the control over if or when to discuss life prolongation to the parent. Emma refused to entertain the thought of initiating the conversation herself, but would be willing to discuss it if her father "gave permission"' by raising the topic himself:

Emma: I just wouldn't instigate it [. . . no I'd rather not [. . .] if he brought the subject up. I would talk to him, but he would have to bring it up (Daughter, 45).

Confidants consider possible strategies that may be used to encourage discussion with relatives

Few confidants had discussed life prolongation with their healthy relatives. The interviewer asked confidants if they could imagine discussing these issues in the future with their relatives. Confidants stressed that conversations about the use of life- prolonging measures would be hard to conduct with the relative concerned, and had difficulty in imagining such discussions in the future. Despite this, most confidants felt it was important to try to discuss life-prolonging measures with their relative. Many suggested ways to introduce the subject.

DG: Do you think there would be ways to make it easier? (Discussing life prolongation). 
Daphne: That would be hard. That would be hard. I suppose, I don't know what would trigger it off, hmmm, I honestly don't know, it would just be one of those things, maybe talking about other people's death (Daughter, 47).

Making it less personal. Confidants thought of different strategies that could be used to make these difficult conversations with their relatives easier, including making it less personal (e.g., talking about someone else's death, like Daphne). This might avoid giving relatives the impression that they were at the stage where they would need their life prolonged. Emma describes how she would approach it:

Emma: Putting things in the first person "if anything happens to me"-make it impersonal for them - to open the discussion, make them think how they feel, and to pick up on what they are saying without them feeling like I'm saying he is (near the end of life) (Daughter, 45).

Social support, family involvement. As they tried to imagine a discussion, confidants spoke of strategies they might use to broach the subject with the family member concerned. Confidants considered calling upon other family members to participate, and planned a discussion prior to actually having it. Myrtle describes how she would get the help of and involve other family members (her brother and her husband) when discussing these issues with her mother.

Myrtle: I would have to probably get one (brother) on my side first and talk about it as it were. I think I would say "ooh yes there was something I wanted to ask you, to talk to you about', and then I would maybe talk to him about it (discussing these issues with their mother). We'd have to then perhaps invite her (mother) over or get the three of us to go out somewhere or even get my husband in on it as well and say that's what we wanted to talk about (Daughter, 65).

The act of imagining the social support provided by involving another family member seemed to make thinking about this hypothetical situation easier. Interestingly, some confidants spoke of having discussions about life prolongation in the case of terminal illness, or when one of their relatives was dying, with other family members, children or siblings, rather than with their dying relative.

Iris: Me and the children will have a discussion and see that we are all thinking the same thing and that we all know what we want (Spouse, 60).

Elizabeth: It couldn't be my sole decision, my brother and my younger sister do need an input on it (Daughter, 48).

Other confidants expected to have these discussions with their relative at a stage where it became apparent that they were ill but before they became mentally incapacitated. Enlisting family support in this stage made it easier and more acceptable.

DG: Under what circumstances might you have this discussion?

Elizabeth: I would think as someone is getting perhaps more ill, unable to do a lot of things for themselves, but mentally alert and agile. I would say other 
family members as well, so that within the boundaries of the family that each would know exactly what the person who is becoming ill wanted. [...] Peter, my brother, my sister Sue and I are going to have to do (this) at some point in the future, with regard to mum obviously. Because we all see her as middleaged woman, but she's 78 and we are going to have to get together as a family and see exactly what mum wants, so that we can follow her wishes (Daughter, 48).

Encouraged by the interview. It seemed that the process of imagining the hypothetical discussion, and the topics covered in the interview as a whole, made the idea of discussing life-prolonging measures a more realistic possibility to almost all confidants.

Agnes: (When I talk) to you (the interviewer) now I just felt that makes you realize, doesn't it, that these things should be talked over (Sister-in-law, 76).

Myrtle: This (interview) would be the opening (Daughter, 65).

Iris: I think when you do go, we'd obviously discuss (it) (Spouse, 60).

\section{Discussion}

Medical and legal guidelines make the assumption that family members discuss issues of life prolongation prior to the relative becoming incapacitated, and that they therefore act in the best interest of the patient while making decisions on life prolongation. However, confidants had rarely discussed life prolongation with their healthy relatives, and tended to draw on their past experience with death, illness, and quality of life when thinking about what might be acceptable for their relatives in relation to life-prolonging technologies. Confidants did not feel that it was the right time to broach these issues with their relatives who were in good health, and some had discouraged their relatives from initiating these conversations. Perhaps this reflected their own anxieties about these issues and was a way of ensuring, unconsciously, that their own views rather than those of their relative would be taken into account when they had to make the final decision regarding life prolongation.

Adult children found it difficult to discuss issues of life prolongation with their older relatives. However, the act of imagining this conversation in the future encouraged confidants to think about strategies that might make these difficult and potentially distressing conversations easier. Strategies included using ideas provoked by the interview as an opener to discussion and enlisting the support of other family members. Confidants were mindful not to upset their relatives by these discussions but were also aware that they potentially would have to make decisions on life prolongation on behalf of their older relative in the future.

Confidants discussed what constituted good and bad deaths, and this guided discussions on their potential involvement in life-prolongation decision-making. The distinction between good and bad deaths has been useful in other qualitative 
studies (e.g., Howarth, 1998), and the distinction has been documented as influencing discussions about life prolongation (Age Concern England, 1999; Winzelberg et al., 2005). Previous research has suggested that community dwelling older adults take into account assessment of quality of life when making decisions about the acceptability of life-prolonging measures (e.g., Carmel \& Mutran, 1997; Cicirelli, 1997; Landon, 2000; Phillips \& Woodward, 1999; Vandrevala et al., 2006). Older adults making decisions about the use of life prolonging medical technologies for themselves in later life based their decisions on the extent to which they might afterwards be mentally or physically impaired (Vandrevala et al., 2006). Interestingly, the findings of the present study suggest that confidants use similar judgements about an acceptable quality of life for their relatives.

This study demonstrates that the experience of being a health-care confidant is affected by powerful past events. These include whether or not the confidant has had experience caring for incapacitated individuals, the relationship with the older person (i.e., one's spouse or as one's parent), and experience of deaths of close relatives and friends. Previous research has suggested that the experience of serious or chronic illness is viewed as grounds for seeing oneself as "really old" (Williams, 1990) during which time the individual discovers the transcendental meaning of life and death (Wong, 1989). When old age encompasses illness and loss of peers and family, it reminds older people and their families of their own mortality and that of those closest to them. Confidants drew on their experiences using narratives of good and bad deaths, and earnestly expressed their wish for good deaths for their relatives. The majority recognized that in some circumstances this would be achieved by withholding life-prolonging technologies.

The present study provides insights into understanding the complex reasons for why confidants thought that discussions on life prolongation were considered inappropriate. Consistent with previous research on older adults (e.g., Vandrevala \& Hampson, 2002), discussions on life prolongation took place at the "right time", this being invariably when serious illness or death of a family member brought the subject to the fore. However, these preliminary findings suggest that despite ill health of the relative and other events that may lead to conversations on life prolongation, confidants may not be comfortable discussing these issues. By avoiding conversations on life prolongation, family members may protect themselves and their loved ones from confronting the painful reality of death and dying. This is consistent with previous studies suggesting that the main barrier to doctors' reluctance to raise the issue of advance care planning is the fear that medical professionals have of destroying hope for the patient (e.g., Davison \& Simpson, 2006). Perhaps family members feel that by broaching these issues with their loved ones, their relatives could interpret these conversations as "giving up" or "losing hope". Additionally, adult children did not want to initiate discussions with older relatives because they found facing their parents' mortality difficult, but when pressed to imagine such a conversation they drew upon family support (Roberto, 1999). These findings may reflect lessening reluctance to discuss death and dying in contemporary Western societies (Clark, 1993; Davis \& Higginson, 2004; Seale, 2000; Timmermans, 1999). 


\section{Initiating life-prolongation discussions}

Suhl et al. (1994) reported that the more discussions the older adult and their family members had regarding older people's feelings about receiving life support, the more accurately the surrogate understood the wishes of their relative regarding life sustaining treatment. Thus, if family members are to be involved in resuscitation decisions, they need to discuss these issues with their relative. The findings of this study may be useful for families and health-care professionals seeking ways to initiate discussions about end-of-life wishes and preferences regarding life-prolonging measures prior to incapacitation. Confidants began the interview scarcely able to contemplate the idea of discussing the topic of end-of-life care with their relatives but, by the end, when they had been encouraged to imagine having the discussion, they were able to describe quite detailed scenarios. It appears that involvement of other family members to help initiate the conversation is important so that all concerned know the relatives' wishes. Confidants recognized that planning was necessary prior to holding a discussion about end-of-life care, and that a trigger was also necessary to get them to plan for the conversation.

Our experience of conducting the interviews suggested that the involvement of a third, neutral party could make such conversations less distressing. More importantly, these interviews helped some confidants evaluate their own beliefs and values about death and dying, thereby making it easier for them to discuss such issues with their loved ones. Although not intended, this study acted as an intervention. By discussing life prolongation with the interviewers, confidants realized that these discussions were not as stressful as they had anticipated. At the end of the interviews, participants commented on the value of the study, often phoned the researchers asking for advice, and informed the researchers that they had initiated these conversations with the member of the family who had participated in the research and other family members. However, in a few cases, confidants found it difficult to even hypothetically contemplate having these discussions, indicating that this is a sensitive topic and can only be raised with people ready and willing to discuss it.

\section{Strengths and limitations}

Strengths of this study include the semi-structured tape-recorded interview that enabled the interviewers to develop the conversation about these difficult and sensitive issues. In addition, the themes identified during interpretative analysis were validated by the involvement of another investigator (TV) in the early stages of analysis. The use of a hypothetical conversation to derive the theme of family involvement may be viewed as a limitation because actual end-of-life discussions may not unfold in the way imagined by these confidants. However, this study provided insights into whether confidants felt comfortable discussing these issues and these conversations acted as an impetus for those who were willing to discuss these issues with their family members.

More research is needed to clarify some of the issues raised in this study, namely whether confidants or family members of terminally ill patients and those of the frail older adults discuss these issues and whether they use similar values and 
judgements when asked about their potential involvement in life-prolongation decision-making. Additionally, little is known about the actual experience of family members as they are involved in life-support decision-making. Identification of the needs of family members to work through the decision-making experience cognitively, emotionally, and morally is essential to communicating effectively about the ill relative's condition and to providing understanding and support to families involved in life-support decision-making in the critical care unit (Swigart et al., 1996).

\section{Conclusion}

Understanding the role of confidants and their families in life-prolongation decision-making is increasingly important as life-prolonging medical technology advances. This study provides a starting point for understanding confidants' perspectives. Family discussions regarding the use of life prolongation should not be conceptualized as a "one-off" conducted at the time of illness or near death, but encouraged as ongoing conversations within the family which begin before the older family member is very ill or frail. An "hypothetical format" could possibly be used to facilitate formal discussions between confidants and their ageing relatives when the time comes. Confidants expressed reluctance to discuss life-prolongation issues with their relatives for a variety of complex reasons. However, by imagining a hypothetical discussion during the course of these interviews, confidants generated a number of strategies that would help them initiate such discussions. These strategies could form the basis of an intervention to assist confidants and their relatives to discuss this highly sensitive topic.

\section{Acknowledgements}

This research was supported by a grant from the Nuffield Foundation, UK. The authors are indebted to all the participants and organizations for their interest in supporting this study.

\section{REFERENCES}

Age Concern England. (1999). The Millennium papers: Values and attitudes in managing society. Glasgow: Age Concern England.

Allen, R. S., \& Shuster, J. L. (2002). The role of proxies in treatment decisions: Evaluating functional capacity to consent to end-of-life treatments within a family context. Behavioural Sciences and Law, 20, $235-252$.

British Medical Association. (2005). End of life decision-making. Views of the BMA. Retrieved April 27, 2006, from http://www.bma.org.uk/ap.nsf/Content/CPRDecisions07

Carmel, S., \& Mutran, E. J. (1997). Preferences for different life sustaining treatments among elderly persons in Israel. Journal of Gerontology: Psychological Sciences and Social Sciences B, 52, S97-S102.

Carpiniello, B., Carta, M., \& Rudas, N. (1989). Depression among elderly people: A psychosocial study of urban and rural populations. Acta Scandinavica, 80, $445-450$.

Cicirelli, V. G. (1997). Relationship of psychosocial and background variables to older adults' end of life decisions. Psychology and Ageing, 12, $72-83$.

Clark, D. (1993). The sociology of death. Oxford: Blackwell Publishers. 
Curtis, J. R., \& Burt, R. A. (2003). Why are critical care clinicians so powerfully distressed by family demands for futile care? Journal of Critical Care, 18(1), $22-24$.

Davis, E., \& Higginson, I. J. (2004). The solid facts: Palliative care. Denmark: World Health Organization Europe. Retrieved January 15, 2005, from http://www.euro.who.int/document/ E82931.pdf/

Davison, S. N., \& Simpson, C. (2006). Hope and advance care planning in patients with end stage renal disease: qualitative interview study. British Medical Journal, 333, 886.

Department of Health. (2001). National service framework for older people. London: HMSO.

Department of Health. (2005). National service framework for long-term conditions. London: HMSO.

Ditto, P. H., Danks, J. H., Smucker, W. D., Bookwala, J., Coppola, K. M., Dresser R., et al. (2001). Advance directives as acts of communication. Archives of Internal Medicine, 161, 421 430.

Edelmann, R. J. (2000). Psychosocial aspects of the health care process. Harlow: Prentice Hall.

Emanuel, J., \& Emanuel, L. (1992). Proxy decision making for incompetent patients: an ethical and empirical analysis. Journal of American Medical Association, 267, 2067 - 2071.

European Federation of Older People. (2004). Making palliative care a priority topic on the European health agenda and recommendations for the development of palliative care in Europe. Graz, Austria: EURAG.

Guarnaccia, C., \& Zautra, A. (1989). Use of confidant reports to assess the affective state of older adults. Clinical Gerontologist, 9, $68-71$.

High, D. M. (1988). All in the family: Extended autonomy and expectations in surrogate health care decision making. The Gerontologist, 28, 46-51.

High, D. M. (1994). Surrogate decision-making: Who will make decisions for me when I can't? Clinics in Geriatric Medicine, 10, $445-461$.

House of Commons. (2004). Mental Capacity Bill. Retrieved January 15, 2004, from http:// www.publications.parliament.uk/pa/cm200304/cmbills/120/2004120.pdf

Howarth, G. (1998). “Just live for today”. Living, caring, ageing and dying. Ageing and Society, 18, $673-689$.

Keith, P. M. (1983). Patterns of assistance among parents and the childless in very old age: Implications for practice. Journal of Gerentological Social Work, 6, 49-59.

Konn, M., \& Menon, G. (1988). Life prolongation: views of elderly outpatients and health care professionals. Journal of the American Geriatric Society, 36, $840-844$.

LANDON, L. (2000). CPR: When is it acceptable to withhold it? A hospital survey of "Not for CPR" orders. Age \& Ageing, 29, 9-16.

Luttrell, S., \& Summerville, A. (1996). Limiting risks of curtailing rights: a response to Dr. Ryan. Journal of Medical Ethics, 27, $274-277$.

National Health Service. (2005). Gold standards programme for England. Prognostic Indicator Paper vs 1.121, 2006. Retrieved May 10, 2007, from www.goldstandardsframework.nhs.uk

National Health Service. (2006). NHS end of life care programme. Retrieved May 10, 2007, from http://eolc.cbcl.co.uk/eolc

Palker, N. B., \& Nettles-Carson, B. (1995). The prevalence of advance directives: Lessons from a nursing home. Nurse Practice, 20, 7-8.

Phillips, K., \& Woodward, V. (1999). The decision to resuscitate: Older people's views. Journal of Clinical Nursing, 8, $753-761$.

Pratt, C. C., Jones, L. L., Hwa-Yong Shin, \& Walker, A. J. (1989). Autonomy and decisionmaking among single older women and their caregiving daughters. The Gerontologist, 29, 792 797.

Puchalski, C. M., Zhong, Z., \& Jacobs, M. M. (2000). Patients who want their family and physician to make resuscitation decisions for them: observations from SUPPORT and HELP. Journal of the American Geriatric Society, 48, $284-290$.

Roberto, K. A. (1999). Making critical health care decisions for older adults: consensus among family members. Family Relations, 48, $167-175$.

Seale, C. (2000). Changing patters of death and dying. Social Science \& Medicine, 51, 917 - 930.

Seckler, A., Meier, D., Mulvihill, M., \& Paris, B. (1991). Substituted judgement: How accurate are proxy predictions? Annals of Internal Medicine, 115, $92-98$.

Seymour, J., Gott, M., Bellamy, G., Ahmedzai, S., \& Clark, C. (2004). Planning for the end of life: the views of older people towards advance care statements. Social Science \& Medicine, 59, $57-68$. 
Sмiтн, J. A. (1996). Beyond the divide between cognition and discourse: Using interpretative phenomenological analysis in health psychology. Psychology and Health, 11, $261-271$.

SMith, J. A., JaRmAn, M., \& Osborn, M. (1999). Doing interpretative phenomenological analysis. In M. Murray \& K. Chamberlain (Eds.), Qualitative Health Psychology. Theories and Methods. London: Sage.

Suhl, J., Simons, P., Reddy, T., \& Garrick, T. (1994). Myth of substituted judgement: Surrogate decision making regarding life support is unreliable. Archives of Internal Medicine, 154, 90 - 96.

SuppoRT. (1995). A controlled trial to improve care for seriously ill hospitalized patients. The study to understand prognoses and preferences for outcomes and risks of treatments (SUPPORT). Journal of American Medical Association, 274, $1591-1598$.

Swigart, V., Lidz, C., Butterworth, V., \& Arnold, R. (1996). Letting go: Family willingness to forgo life support. Heart Lung, 25, $483-494$.

Timmermans, S. (1999). Sudden death and the myth of CPR. Philadelphia: Temple University Press.

Uhlmann, R. F., Pearlman, R. A., \& Cain, K. C. (1988). Physicians' and their spouses' predictions of elderly patients' resuscitation preferences. Journal of Gerontology, 43, M115 M121.

Vandrevala, T., \& Hampson, S. E. (2002). Breaking the death taboo: Older people's perspectives on end of life decisions. Quality in Ageing: Policy, practice and research, 3, 36-46.

Vandrevala, T., Hampson, S. E., Daly, T., Arber, S., \& Thomas, H. (2006). Dilemmas in decision making about resuscitation: A focus group study of older people. Social Science and Medicine, 62, $1579-1593$.

Volicer, L., Cantor, M. D., Derse, A. R., Edwards, D. M., Murray Edwards, D., Prudhomme, A. M., et al. (2002). Advance care planning by proxy for residence of long-term facilities who lack decision-making capacity. Journal of American Geriatrics Society, 50, 761 - 762.

Wenger, C. G., \& Jerrome, D. (1999). Change and stability in confidant relationships: Findings from the Bangor Longitudinal Study of Ageing. Journal of Ageing Studies, 13, $269-294$.

Williams, R. (1990). A Protestant legacy: Attitudes to death and illness among older Aberdonians. Oxford: Clarendon Press.

Winzelberg, G. S., Hanson, L. S., \& Tulsky, J. A. (2005). Beyond autonomy: Diversifying endof-life decision-making approaches to serve patients and families. Journal of American Geriatrics Society, 53, 1046.

Wong, P. T. P. (1989). Successful aging and personal meaning. Canadian Psychology, 30, 516-525. 